\title{
Does Herding Behavior Exist in the IDX Sectoral Indices
}

\author{
Ananda Anggara S \\ Mercu Buana University, Jakarta, Indonesia
}

\begin{abstract}
This study aims to detect herding behavior based on cross-sectional dispersion in certain market conditions using CSAD method as proposed by Chiang, Li, \& Tan (2010). CSAD method allows researchers to evaluate if there is a herding behavior in the capital market. This research uses 9 (nine) sectoral indices listed on the Indonesia Stock Exchange (IDX) in the 2013-2019 period. This study examines the hypothesis that herding behavior occurs in the sectoral indices of the Indonesia stock market in upward market conditions and downward market conditions. The results showed that herding behavior occurred in all of the sectoral indices in downward market condition, but herding behavior was not indicated at all in upward market condition.
\end{abstract}

Keywords:- behavioral finance, herding behavior, CSAD, return, quantile regression.

\section{INTRODUCTION}

In the 1970s, an idea emerged regarding the efficient market hypothesis (Shiller, 2003). According to Fama (1970), this theory states that the selection of financial assets, especially stocks, is influenced by the rational attitude of investors where investors choose stocks based on information available in the public.

In fact, investor behavior is not as rational as suggested by the efficient market hypothesis. When there is market turmoil, the falling share price tends to be responded by other investors by selling shares, which causes the share price to fall further. This is because humans tend to see what other people are doing and sometimes follow it by ignoring their analytical skills (Lao \& Singh, 2011). In the 1990s, this was realized and academics began to shift the focus of discussion from econometric analysis of prices, dividends, and income towards developing human psychological models related to financial markets, known as behavioral finance (Shiller, 2003).

One aspect of behavioral finance that has become the focus of academics is herding behavior. Herding behavior in financial markets can be identified as a tendency for investor behavior to follow other investors' investment decisions (Phuoc Luong \& Thi Thu Ha, 2011). When herding behavior occurs, stock prices in the stock market do not reflect both fundamental and non-fundamental information so that the probability of being overvalued and undervalued is relatively high, which has implications for increasing the likelihood of investors getting an abnormal return (Hwang \& Salmon, 2004).

\author{
Matrodji H. Mustafa \\ Mercu Buana University, Jakarta, Indonesia
}

According to Chang, Cheng, \& Khorana (2000), herding behavior tends to occur when market stress conditions happen in emerging markets and is less likely to occur in developed markets. Chiang \& Zheng (2010) then found evidence that herding behavior occurs globally both when the market is down and is on the rise, except for the markets of the United States and Latin America. In the United States and Latin America markets, herding behavior is indicated only during a crisis. In line with this research, Tan, Chiang, Mason, \& Nelling (2008) also found significant evidence of herding behavior in Indonesia, Malaysia, Singapore, and Thailand. Slightly different from these studies, Gunawan, Achsani, \& Rahman (2011) provide evidence that herding behavior only occurs during market stress conditions in the Indonesia capital market. Under normal conditions and high yields, herding behavior does not occur.

As adapted from Bank Indonesia (2009), the facts show that the herding phenomenon is thought to be one of the factors that caused the rupiah to drop along with excessive fluctuations with depreciation reaching around 85\% in the July 1997-June 1998 period. IDX Composite Index has decreased which was very sharp, namely $62 \%$ in the period June 1997-September 1998. Meanwhile, the yield on government securities increased sharply to $16 \%$ during the 'mini' crisis in 2005, while the IDX Composite Index had dropped to the level of 1,058.51. During the economic crisis in 2008, the IDX Composite Index decreased by 54\%, while the yield on SUN was corrected by around $20 \%$ in the February 2008-November 2008 period. Therefore, detecting herding behavior on a stock market is needed to see the rationality of investors in various conditions.

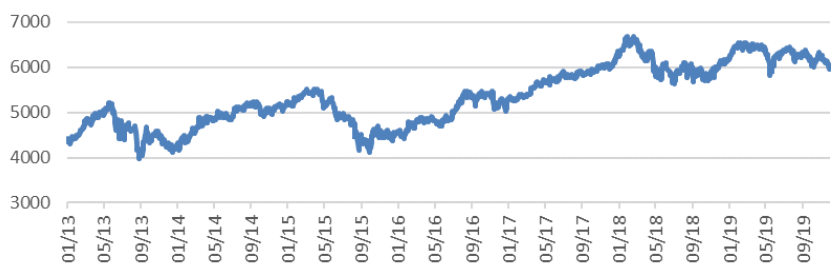

Fig 1:- IDX Composite Index Movement January 2013December 2019

As can be seen in Fig. 1, IDX Composite Index also experienced a sharp decline after experiencing a fairly high increase in 2013, 2015 and 2018. However, little to no research discusses the role and behavior of herding during that period, whether herding behavior also occurred in 20132019 as happened in the period 1997-1998 and 2008 as reported by Bank Indonesia (2009). 


\section{THEORY STUDY}

\section{A. Efficient Market Hypothesis}

Fama (1970) provides an understanding that the concept of an efficient market means that the current stock price reflects all available information and can be categorized into three, namely the weak form; semi-strong form; and strong form. According to Gumanti \& Utami (2002), if the weak form efficient market hypothesis is fulfilled, the result is that price changes will follow a random walk method. A simple example of applying the method of random walking is the tossing of a coin, in which, for example, one side has head image and tree on the other side. Even though the first three throws come out head image, that does not mean that the next throw will come out head image again. Because securities offer positive returns, we can expect that stock prices will continue to increase or appreciate over time. But the upward trend or trend will not always be like that, because price changes follow a random path. Whereas in the semi-strong form of efficient market concept, investors will not be able to obtain abnormal returns by using strategies that are built based on publicly available information. The idea of this view is that once the information becomes public (general) information, meaning that it is spread across the market, all investors will react quickly and push prices up to reflect all available public information. Finally, the strong form efficient market is the strictest form of the efficient market hypothesis. This is related to the understanding that market prices reflect all information, both public and nonpublic. In this regard, in the context of a strong efficient market, no one, either individual or institution, can get an abnormal return.

\section{B. Behavioral Finance}

In the 1990s, academics began to shift the focus of discussion from econometric analysis of prices, dividends, and income to developing human psychological models related to financial markets, known as behavioral finance (Shiller, 2003). According to Lintner (1998), behavioral finance is a science that studies how humans disclose and react to existing information to make decisions that can optimize returns by paying attention to the risks inherent in it (elements of human attitudes and actions are determining factors in investing).

There are two perspectives on herding behavior rational and irrational. From an irrational perspective, herding behavior can be defined as the behavior of individuals to suppress their own beliefs and base investment decisions solely on collective market actions, although they do not agree with the predicted results in reality (Christie, et al., 1995; Lao, et al., 2011). From a rational perspective, herding behavior occurs when lowability managers deliberately mimic the actions of more senior investors to maintain their reputation, thus ignoring their information because they believe other people's decisions are more informed. (Devenow and Welch, 1996; Lao, et al., 2011).

\section{Herding Behavior}

One aspect of behavioral finance that has become the focus of academics is herding behavior. Herding behavior in financial markets can be identified as a tendency for investor behavior to follow other investors' investment decisions (Phuoc Luong, et al., 2011). There are several methods for detecting herding behavior, such as CSSD (Christie \& Huang, 1995) and CSAD (Chang, Cheng, \& Khorana, 2000).

Christie et al (1995) used the cross-sectional standard of return (CSSD) method. This method uses a measure to detect herding behavior over a period of time when there is an extreme up or down push in yields. In simple terms, it can be explained that this method tries to measure the average proximity of individual stocks returns to the average market returns. In the other hand, the method of Chang et al (2000) describes the relationship between cross-sectional absolute standard deviation (CSAD) and market returns. At the extreme, if investors follow market consensus and ignore personal opinion, then the increasing linear relationship between market spread and returns is no longer valid, but the relationship can be a non-linear increase or decrease.

\section{THINKING FRAMEWORK}

The analysis in this study uses quantile regression analysis between CSAD and market portfolio returns as described by Chiang, et al. (2010). The framework can be described as follows:

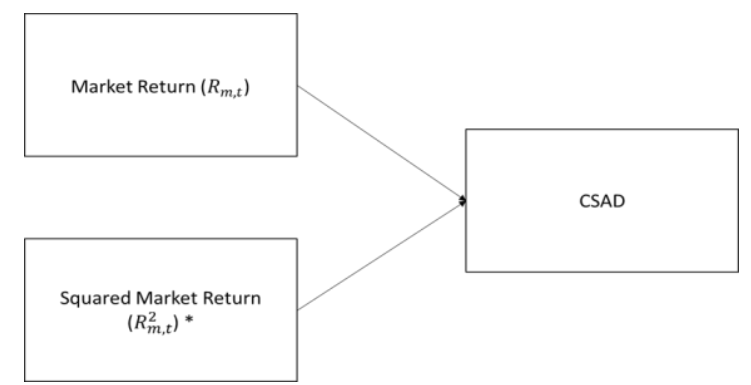

Fig 2:- Thinking Framework

Usually, the behavior of investors who follow other investors occurs when market conditions go up or down because there is a view that investors must follow the current trend to get a profit in investing, as a phrase that often appears in the investment world "The trend is your friend". Research by Luo \& Schinckus (2014) in Shanghai and Shenzhen stock exchange markets found an indication of herding behavior in upward market conditions and downward market conditions. Hwang, et al. (2004) also found that herding behavior occurs in the American and South Korean capital markets when the market is down or is on the rise. Based on the explanation, the hypothesis of this research is:

$>$ there was herding behavior on the IDX sectoral indices in upward market conditions

$>$ there was herding behavior on the IDX sectoral indices in downward market conditions 


\section{RESEARCH METHODS}

\section{A. Research Design}

This study aims to describe and explain whether there is herding behavior in sectoral indices listed on the IDX in terms of upward market conditions and downward market conditions in the period March 2013- December 2019.

\section{B. Data / Information Sources}

The type and source of data used in the study were secondary quantitative data, namely data obtained by researchers indirectly through intermediary media. The data obtained by researchers is the daily price movement data.

\section{Population and Samples}

This study uses the IDX sectoral indices population data. The sample of this research is all sectoral indices daily data listed on the IDX as of March 2013-December 2019. The objects of research are according to the criteria set, namely the 9 (nine) sectoral indices of the IDX as follows:

\begin{tabular}{|c|c|c|}
\hline $\begin{array}{c}\mathrm{N} \\
\mathrm{o}\end{array}$ & Index Name & $\begin{array}{c}\text { Resear } \\
\text { ch } \\
\text { Code }\end{array}$ \\
\hline $\mathbf{1}$ & Agriculture Index & AGRI \\
\hline $\mathbf{2}$ & Mining Index & MING \\
\hline $\mathbf{3}$ & Basic Industry and Chemical Index & BIND \\
\hline $\mathbf{4}$ & Miscellaneous Industry Index & MISC \\
\hline $\mathbf{5}$ & Consumer Goods Industry Index & CONS \\
\hline $\mathbf{6}$ & Property, Real Estate and Building & PROP \\
\hline $\mathbf{7}$ & Construction Index & \\
\hline $\mathbf{8}$ & Infrastructure, Utilities and Transportation & INFA \\
\hline $\mathbf{9}$ & Trade, Services and Investment Index & TRAD \\
\hline
\end{tabular}

Table 1:- List of Sectoral Indices on the Indonesia Stock Exchange

\section{Data Analysis Method}

The regression model to examine herding behavior is based on the robust approach proposed by Chiang, et al. (2010) based on the method of Chang, et al. (2000). With CSAD as the dependent variable and market return as the independent variable. Chiang, et al. (2010) used a more robust quantile regression and consequently produced a more efficient estimate since it was possible to cover a wide range of quantile functions.

Cross-Sectional Absolute Deviation, as measured by the method of Chang, et al. (2000) to detect herding behavior through cross-sectional data on security returns without the need to estimate beta values, as follows:

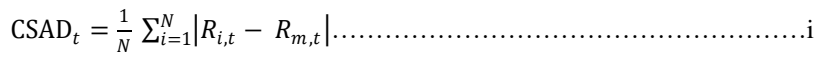

During periods of extreme market movements, some academics argue that the relation between the dispersion of returns and market returns becomes nonlinear when conditions rise or fall. To detect herding behavior in the above conditions, Chang, et al. (2000) modified the formula to be:

$$
\operatorname{CSAD}_{t}=\alpha+y_{1}\left|R_{m, t}\right|+y_{2} R_{m, t}^{2}+\varepsilon
$$

To be more specific in estimating the possibility of the asymmetric effect of herding behavior when market conditions go up and the market falls, the researchers adopted the robust approach proposed by Chiang et al. (2010) based on the method of Chang, et al. (2000) as follows:

$$
\begin{aligned}
& \operatorname{CSAD}_{t}=\alpha+y_{1}\left(1-D_{t}\right) R_{m, t}+y_{2} D_{t} R_{m, t}+y_{3}\left(1-D_{t}\right) R_{m, t}^{2}+ \\
& y_{4} D_{t} R_{m, t}^{2}+\varepsilon
\end{aligned}
$$

The formulation is made by dividing the data into two (2) groups using dummy variable D. Variable D is 1 if the market portfolio return is negative and is 0 otherwise. To determine the herding behavior in upward market conditions, the coefficient $y_{3}$ is negative and significant. To determine the herding behavior in a down market condition, the coefficient $y_{4}$ is negative and significant.

\section{RESEARCH RESULTS AND DISCUSSION}

Testing to determine the presence of herding behavior was carried out using quantile regression analysis as adopted from Chiang et al. (2010). Briefly, quantile regression is a statistical procedure designed to estimate conditional quantiles. Researchers used 5 (five) outliers in this study, namely $5 \%, 25 \%, 50 \% 75 \%$, and $90 \%$. The use of 5 (five) outliers with a range of $5 \%-90 \%$ is selected after trial and error process is carried out so that the research can show the gradation of the coefficient of determination (R2) - a measure of the goodness of the model - in each market

\begin{tabular}{|c|c|c|c|c|c|c|}
\hline \multicolumn{2}{|c|}{ AGRI } & $\gamma 1$ & $\gamma^{2}$ & $\gamma 3$ & $\gamma 4$ & Pseudo R- \\
\hline \multirow[t]{2}{*}{$\tau=5 \%$} & Coefficient & 0.074479 & -0.12237 & 0.67895 & -0.39093 & 0.710692 \\
\hline & Prob. & 0 & 0 & 0 & 0.0639 & \\
\hline \multirow[t]{2}{*}{$\tau=25 \% *$} & Coefficient & 0.091551 & -0.11954 & 0.379415 & -0.22063 & 0.813745 \\
\hline & Prob. & 0 & 0 & 0.4429 & 0.0012 & \\
\hline \multirow[t]{2}{*}{$\tau=50 \% *$} & Coefficient & 0.096036 & -0.12031 & 0.377755 & -0.19031 & 0.849693 \\
\hline & Prob. & 0 & 0 & 0.122 & 0.0001 & \\
\hline \multirow[t]{2}{*}{$\tau=75 \%$ * } & Coefficient & 0.093167 & -0.12152 & 0.597607 & -0.19534 & $0.86684 \epsilon$ \\
\hline & Prob. & 0 & 0 & 0.0129 & 0.0052 & \\
\hline \multirow[t]{2}{*}{$\tau=90 \%$} & Coefficient & 0.082827 & -0.12104 & 1.170896 & -0.06917 & 0.871395 \\
\hline & Prob. & 0 & 0 & 0.05 & 0.1597 & \\
\hline
\end{tabular}
condition. The quantile regression results for the Sectoral Indices on the IDX are as follows.

\section{A. Agriculture Index (AGRI)}

Table 2:- Agriculture Index Test Results

The quantile regression results on the Agricultural Index show that the coefficient y_(3 ) in all quantiles does not produce negative values.Meanwhile,the quantile regression results on the $\mathrm{y}_{-} 4$ coefficient shows that for all quantiles, the y_4 coefficient has a negative value.However,the significant coefficient y_4 was only 
ISSN No:-2456-2165

found in $25 \%, 50 \%$ and $75 \%$ quantiles. This is evidenced by the probability value $\mathrm{y}_{-} 4$ at $25 \%, 50 \%$ and $75 \%$ quantiles less than $0.05(0.0012 ; 0.0001 ; 0.0052)$.

\section{B. Mining Index (MING)}

$$
\begin{array}{llrrrrr}
\multicolumn{2}{c}{\text { MING }} & \multicolumn{1}{c}{\gamma 1} & \multicolumn{2}{c}{\gamma 2} & \multicolumn{1}{c}{\gamma \text {. }} & \multicolumn{1}{c}{\begin{array}{c}
\text { Pseudo R- } \\
\text { Squared }
\end{array}} \\
\tau=5 \% & \text { Coefficient } & 0.080979 & -0.12373 & 0.55818 & -0.40448 & 0.730969 \\
& \text { Prob. } & 0 & 0 & 0 & 0.198 & \\
\tau=25 \% * & \text { Coefficient } & 0.092111 & -0.11828 & 0.384297 & -0.18027 & 0.826107 \\
& \text { Prob. } & 0 & 0 & 0 & 0.0023 & \\
\tau=50 \% * & \text { Coefficient } & 0.095212 & -0.12025 & 0.426731 & -0.22971 & 0.861086 \\
& \text { Prob. } & 0 & 0 & 0.0011 & 0 & \\
\tau=75 \% * & \text { Coefficient } & 0.093573 & -0.12121 & 0.591944 & -0.25731 & 0.880671 \\
& \text { Prob. } & 0 & 0 & 0.0046 & 0.001 & \\
\tau=90 \% * & \text { Coefficient } & 0.087132 & -0.12337 & 0.95063 & -0.25464 & 0.893068 \\
& \text { Prob. } & 0 & 0 & 0.0429 & 0 &
\end{array}
$$

Table 3:- Mining Index Test Results

The quantile regression results on the Mining Index show that the coefficient y_(3 )in all quantiles does not produce negative values. Meanwhile, the quantile regression results on the y_4 coefficient shows that for all quantiles, the $y_{-} 4$ coefficient has a negative value. However, the significant coefficient y_4 was only found in $25 \%, 50 \%$, $75 \%$, and $90 \%$ quantiles. This is evidenced by the probability value $\mathrm{y}_{-} 4$ in $25 \%, 50 \%, 75 \%$, and $90 \%$ quantiles smaller than $0.05(0.0023 ; 0 ; 0.001 ; 0)$.

\section{Basic Industry and Chemical Index (BIND)}

\begin{tabular}{|c|c|c|c|c|c|c|}
\hline BIND & & $\gamma 1$ & $\gamma^{2}$ & $\gamma 3$ & $\gamma 4$ & $\begin{array}{l}\text { Pseudo R- } \\
\text { Squared }\end{array}$ \\
\hline \multirow[t]{2}{*}{$\tau=5 \%$} & Coefficient & 0.087095 & -0.12346 & 0.438903 & -0.39396 & 0.765829 \\
\hline & Prob. & 0 & 0 & 0.0001 & 0.1717 & \\
\hline \multirow[t]{2}{*}{$\tau=25 \% *$} & Coefficient & 0.094644 & -0.1189 & 0.391485 & -0.2081 & 0.85115 \\
\hline & Prob. & 0 & 0 & 0 & 0.0001 & \\
\hline \multirow[t]{2}{*}{$\tau=50 \% *$} & Coefficient & 0.097152 & -0.11967 & 0.469911 & -0.17535 & 0.882039 \\
\hline & Prob. & 0 & 0 & 0 & 0.0013 & \\
\hline \multirow[t]{2}{*}{$\tau=75 \% *$} & Coefficient & 0.095817 & -0.12045 & 0.536459 & -0.1712 & 0.899281 \\
\hline & Prob. & 0 & 0 & 0.0004 & 0 & \\
\hline \multirow[t]{2}{*}{$\tau=90 \% *$} & Coefficient & 0.090346 & -0.1223 & 0.76633 & -0.22329 & 0.910427 \\
\hline & Prob. & 0 & 0 & 0.0177 & 0 & \\
\hline
\end{tabular}

Table 4:- Basic Industry and Chemical Index Test Results

The quantile regression results on the Basic Industry And Chemical Index show that the coefficient y_(3 )in all quantiles does not produce negative values. Meanwhile, the quantile regression results on the y_ 4 coefficient shows that for all quantiles, the $y_{-} 4$ coefficient has a negative value. However, the significant coefficient $\mathrm{y}_{-} 4$ was only found in $25 \%, 50 \%, 75 \%$, and $90 \%$ quantiles. This is evidenced by the probability value $\mathrm{y}_{-} 4$ in $25 \%, 50 \%, 75 \%$, and $90 \%$ quantiles smaller than $0.05(0.0001 ; 0.0013 ; 0 ; 0)$.

$$
\begin{aligned}
& \underset{\text { MISC }}{\text { D. Miscellaneous Industry }} \underset{\gamma 1}{\operatorname{Index}}(\mathrm{MISC}) \\
& \begin{array}{cccccc}
\text { MISC } & \gamma 1 & \gamma 2 & \gamma 3 & \gamma 4 & \begin{array}{c}
\text { Pseudo R- } \\
\text { Squared }
\end{array}
\end{array} \\
& \begin{array}{lrrrrrr}
\tau=5 \% & \text { Coefficient } & 0.075142 & -0.12447 & 0.654463 & -0.42297 & 0.715055 \\
& \text { Prob. } & 0 & 0 & 0 & 0.0309 &
\end{array} \\
& \tau=25 \% * \quad \text { Coefficient } \quad 0.086568 \quad-0.12071 \quad 0.580752 \quad-0.25229 \quad 0.809139 \\
& \begin{array}{llrrrrr} 
& \text { Prob. } & 0 & 0 & 0 & 0.0001 & \\
\tau=50 \% * & \text { Coefficient } & 0.092455 & -0.12458 & 0.468494 & -0.34869 & 0.849103
\end{array} \\
& \begin{array}{llrrrrr} 
& \text { Prob. } & 0 & 0 & 0 & 0 & \\
\tau=75 \% * & \text { Coefficient } & 0.0898 & -0.12466 & 0.712229 & -0.31002 & 0.87356 \\
& \text { Prob. } & 0 & 0 & 0.0006 & 0.0021 & \\
\tau=90 \% * & \text { Coefficient } & 0.082944 & -0.12153 & 0.973585 & -0.20515 & 0.887725
\end{array} \\
& \begin{array}{lllll}
\text { Prob. } & 0 & 0 & 0.0021 & 0
\end{array}
\end{aligned}
$$

Table 5:- Miscellaneous Industry Index Test Results

The quantile regression results on the Miscellaneous Industry Index show that the coefficient $y_{3}$ in all quantiles does not produce negative values. Meanwhile, the quantile regression results on the $y_{4}$ coefficient shows that for all quantiles, the $y_{4}$ coefficient has a negative value. However, the significant coefficient $y_{4}$ was only found in $25 \%, 50 \%$, $75 \%$, and $90 \%$ quantiles. This is evidenced by the probability value $y_{4}$ in $25 \%, 50 \%, 75 \%$, and $90 \%$ quantiles smaller than $0.05(0.0001 ; 0 ; 0.0021 ; 0)$.

\section{E. Consumer Goods Industry Index (CONS)}

\begin{tabular}{llrrrrr} 
CONS & & \multicolumn{2}{c}{$\gamma 1$} & \multicolumn{2}{c}{$\gamma 2$} & \multicolumn{2}{c}{$\gamma$ Ps } & \multicolumn{1}{c}{$\begin{array}{c}\text { Pseudo R- } \\
\text { Squared }\end{array}$} \\
$\tau=5 \%$ & Coefficient & 0.086693 & -0.12256 & 0.450899 & -0.39033 & 0.773653 \\
& Prob. & 0 & 0 & 0 & 0.1082 & \\
$\tau=25 \% *$ & Coefficient & 0.095322 & -0.11839 & 0.325835 & -0.19665 & 0.852982 \\
& Prob. & 0 & 0 & 0 & 0 & \\
$\tau=50 \% *$ & Coefficient & 0.097619 & -0.11904 & 0.389069 & -0.19565 & 0.885038 \\
& Prob. & 0 & 0 & 0 & 0.0001 & \\
$\tau=75 \% *$ & Coefficient & 0.096608 & -0.11968 & 0.480851 & -0.11571 & 0.904117 \\
& Prob. & 0 & 0 & 0.0006 & 0 & \\
$\tau=90 \% *$ & Coefficient & 0.090423 & -0.12111 & 0.841046 & -0.15326 & 0.917168 \\
& Prob. & 0 & 0 & 0.118 & 0 &
\end{tabular}

Table 6:- Consumer Goods Industry Index Test Results

The quantile regression results on the Consumer Goods Industry Index (table VI) show that the coefficient y_(3 )in all quantiles does not produce negative values. Meanwhile, the quantile regression results on the $y_{-} 4$ coefficient shows that for all quantiles, the y_4 coefficient has a negative value. However, the significant coefficient y_4 was only found in $25 \%, 50 \%, 75 \%$, and $90 \%$ quantiles. This is evidenced by the probability value y_4 in $25 \%$, $50 \%, 75 \%$, and $90 \%$ quantiles smaller than $0.05(0 ; 0.0001$; $0 ; 0)$. 


\section{F. Property, Real Estate and Building Construction Index} (PROP)

\begin{tabular}{llrrrrr} 
PROP & & \multicolumn{1}{c}{$\gamma 1$} & \multicolumn{1}{c}{$\gamma 2$} & \multicolumn{1}{c}{$\gamma 4$} & $\begin{array}{c}\text { Pseudo R- } \\
\text { Squared }\end{array}$ \\
$\tau=5 \% *$ & Coefficient & 0.093736 & -0.12381 & 0.310992 & -0.41303 & 0.787604 \\
& Prob. & 0 & 0 & 0.0001 & 0.0185 & \\
$\tau=25 \% *$ & Coefficient & 0.097134 & -0.11919 & 0.317986 & -0.24604 & 0.864376 \\
& Prob. & 0 & 0 & 0 & 0.0029 & \\
$\tau=50 \% *$ & Coefficient & 0.099414 & -0.11916 & 0.34546 & -0.22257 & 0.891148 \\
& Prob. & 0 & 0 & 0 & 0 & \\
$\tau=75 \% *$ & Coefficient & 0.097975 & -0.12265 & 0.464001 & -0.26703 & 0.907806 \\
& Prob. & 0 & 0 & 0.0034 & 0 & \\
$\tau=90 \% *$ & Coefficient & 0.090584 & -0.12002 & 0.845824 & -0.11733 & 0.917958 \\
& Prob. & 0 & 0 & 0.0154 & 0.0032 &
\end{tabular}

Table 7:- Property, Real Estate and Building Construction Index Test Results

The quantile regression results on the Property, Real Estate, and Building Construction Index show that the y_3 coefficient in all quantiles does not produce negative values. Meanwhile, the quantile regression results on the $\mathrm{y}_{-} 4$ coefficient shows that for all quantiles, the y_4 coefficient has a negative value. With all the coefficients y_4 shows significant results. This is evidenced by the probability value y_4 in $5 \%, 25 \%, 50 \%, 75 \%$, and $90 \%$ quantiles which is smaller than 0.05 (0.0185; 0.0029; $0 ; 0 ; 0.0032)$.

\section{G. Infrastructure, Utilities and Transportation Index (INFA)}

The quantile regression results on the Infrastructure, Utility, and Transportation Index (table VIII) show that the y_3 coefficient in all quantiles does not produce negative values. Meanwhile, the quantile regression results on the y_4 coefficient shows that for all quantiles, the y_4 coefficient has a negative value. However, the significant coefficient y_4 was only found in $25 \%, 50 \%, 75 \%$, and $90 \%$ quantiles. This is evidenced by the probability value y_4 in $25 \%, 50 \%, 75 \%$, and $90 \%$ quantiles smaller than 0.05 (0.0009; 0; 0.0059; 0.0003).

\begin{tabular}{llrrrrr} 
INFA & & \multicolumn{1}{c}{$\gamma 1$} & \multicolumn{2}{c}{$\gamma 2$} & \multicolumn{1}{c}{$\gamma 4$} & $\begin{array}{c}\text { Pseudo R- } \\
\text { Squared }\end{array}$ \\
$\tau=5 \%$ & Coefficient & 0.097995 & -0.12761 & 0.243331 & -0.58996 & 0.798095 \\
& Prob. & 0 & 0 & 0 & 0.062 & \\
$\tau=25 \% *$ & Coefficient & 0.096925 & -0.11867 & 0.339075 & -0.20175 & 0.865276 \\
& Prob. & 0 & 0 & 0 & 0.0009 & \\
$\tau=50 \% *$ & Coefficient & 0.099384 & -0.11907 & 0.343692 & -0.20559 & 0.894112 \\
& Prob. & 0 & 0 & 0.0009 & 0 & \\
$\tau=75 \% *$ & Coefficient & 0.095712 & -0.11954 & 0.575864 & -0.21223 & 0.909105 \\
& Prob. & 0 & 0 & 0.008 & 0.0059 & \\
$\tau=90 \% *$ & Coefficient & 0.08796 & -0.12063 & 0.967087 & -0.17556 & 0.923259 \\
& Prob. & 0 & 0 & 0.0097 & 0.0003 &
\end{tabular}

Table 8:- Infrastructure, Utilities and Transportation Index Test Results

\section{H. Financial Index (FINA)}

\begin{tabular}{llrrrrr} 
FINA & & \multicolumn{1}{c}{$\gamma 1$} & \multicolumn{2}{c}{$\gamma 2$} & \multicolumn{1}{c}{$\gamma 4$} & $\begin{array}{c}\text { Pseudo R- } \\
\text { Squared }\end{array}$ \\
$\tau=5 \%$ & Coefficient & 0.093812 & -0.12293 & 0.331903 & -0.40729 & 0.810668 \\
& Prob. & 0 & 0 & 0 & 0.0651 & \\
$\tau=25 \% *$ & Coefficient & 0.098847 & -0.11773 & 0.297235 & -0.16007 & 0.880021 \\
& Prob. & 0 & 0 & 0 & 0 & \\
$\tau=50 \% *$ & Coefficient & 0.101104 & -0.11906 & 0.257677 & -0.19983 & 0.906457 \\
& Prob. & 0 & 0 & 0.0019 & 0 & \\
$\tau=75 \% *$ & Coefficient & 0.099682 & -0.11897 & 0.362703 & -0.14396 & 0.922278 \\
& Prob. & 0 & 0 & 0 & 0 & \\
$\tau=90 \% *$ & Coefficient & 0.094491 & -0.12005 & 0.664933 & -0.17246 & 0.9343 \\
& Prob. & 0 & 0 & 0.1018 & 0 &
\end{tabular}

Table 9:- Financial Index Test Results

The quantile regression results on the Financial Index show that the $y_{3}$ coefficient in all quantiles does not produce negative values. Meanwhile, the quantile regression results on the $y_{4}$ coefficient shows that for all quantiles, the $y_{4}$ coefficient has a negative value. However, the significant coefficient $y_{4}$ was only found in $25 \%, 50 \%, 75 \%$, and $90 \%$ quantiles. This is evidenced by the probability value $y_{4}$ in $25 \%, 50 \%, 75 \%$, and $90 \%$ quantiles smaller than $0.05(0 ; 0$; $0 ; 0)$.

\section{Trade, Services and Investment Index (TRAD)}

\begin{tabular}{llrrrrr} 
TRAD & & \multicolumn{1}{c}{$\gamma 1$} & \multicolumn{2}{c}{$\gamma 2$} & \multicolumn{1}{c}{$\gamma 3$} & \multicolumn{1}{c}{$\begin{array}{c}\text { Pseudo R- } \\
\text { Squared }\end{array}$} \\
$\tau=5 \%$ & Coefficient & 0.099196 & -0.124 & 0.190095 & -0.43749 & 0.837381 \\
& Prob. & 0 & 0 & 0.0052 & 0.0556 & \\
$\tau=25 \% *$ & Coefficient & 0.099016 & -0.11703 & 0.268652 & -0.15694 & 0.891508 \\
& Prob. & 0 & 0 & 0.3308 & 0.0006 & \\
$\tau=50 \% *$ & Coefficient & 0.099862 & -0.11702 & 0.319114 & -0.14145 & 0.914067 \\
& Prob. & 0 & 0 & 0 & 0 & \\
$\tau=75 \% *$ & Coefficient & 0.098608 & -0.11705 & 0.402695 & -0.10077 & 0.927229 \\
& Prob. & 0 & 0 & 0.0001 & 0 & \\
$\tau=90 \% *$ & Coefficient & 0.094808 & -0.119 & 0.622167 & -0.14583 & 0.937538 \\
& Prob. & 0 & 0 & 0.0482 & 0.0043 &
\end{tabular}

Table 10:- Trade, Services and Investment Index Test Results

The quantile regression results on the Trade, Services and Investment Index show that the $y_{3}$ coefficient in all quantiles does not produce negative values. Meanwhile, the quantile regression results on the $y_{4}$ coefficient shows that for all quantiles, the $y_{4}$ coefficient has a negative value. However, the significant coefficient $y_{4}$ was only found in $25 \%, 50 \%, 75 \%$, and $90 \%$ quantiles. This is evidenced by the probability value $y_{4}$ in $25 \%, 50 \%, 75 \%$, and $90 \%$ quantiles smaller than $0.05(0.0006 ; 0 ; 0 ; 0.0043)$. 


\section{J. Discussion}

Based on the results of the research that has been done, the results show that there is an indication of herding behavior in the downward market condition in all of Indonesia stock market sectoral indices but there is no indication of herding behavior in upward market condition. The indication of herding behavior occurs in a downward market condition and does not occur in an upward market condition is in line with research results from Chang, et al. (2000); Chiang, et al. (2010); Chiang, et al. (2010); Lao, et al., (2011); and Gunawan, et al. (2011) who found that herding tends to occur under market stress conditions. During market stress, investors tend to suppress their thinking and follow market consensus more, so herding behavior tends to occur during this period. The absence of herding in upward market conditions illustrates that investors tend to behave rationally in making investment decisions based on information available in the market rather than following market consensus.

Chang, et al. (2000) provided an explanation for his research which found that herding tends to occur in emerging markets, especially during market stress conditions. In this study, it was found that herding occurred in emerging markets, namely South Korea and Taiwan because herding behavior could be influenced by several factors such as government intervention, either in monetary policy or direct buying/selling on the stock market as well as limited information factors related to stock market conditions.

According to Chang, et al. (2000) when market conditions are inefficient, investors' knowledge of the company's fundamental information is very limited, allowing them to make decisions based on other signals. Another factor is that there are more speculators on the South Korean and Taiwan stock markets than investors. According to Froot, Scharfstein, and Stein (1992), the presence of a short-term speculator can cause the quality of information to be inefficient. If investors focus on one source of information or there is no variety of information, it can produce a near dispersion rate of return. Bikhchandani \& Sharma (2000) revealed that when they have limited information, investors tend to follow the movements of other investors in making investment decisions which in the end will ignore their own signals and follow the majority decision (herding behavior).

\section{CONCLUSIONS \& SUGGESTION}

\section{A. Conclusions}

Based on the research results to describe and explain whether there is herding behavior on the sectoral indices recorded in the IDX in terms of upward market conditions and downward market conditions in the period March 2013December 2019, as well as the introduction, theoretical studies, data processing, and the discussion that was carried out in the previous chapter, it is known that the research conclusions are as follows:

$>$ No indication of herding behavior was found in upward market conditions in all of the sectoral indices of
Indonesia stock exchange, either in the 5\%, 25\%, 50\%, $75 \%$, or $90 \%$ quantiles.

$>$ An indication of herding behavior was found in downward market conditions in all of the sectoral indices of Indonesia stock exchange. Herding behavior was generally detected in the $25 \%, 50 \%, 75 \%$, and $90 \%$ quantiles except for the Agricultural Index where herding behavior was not found in the $90 \%$ quantile and the Property, Real Estate, and Building Construction Index where herding behavior was found across all study quantiles.

\section{B. Suggestion}

Following are suggestions that can be used as a reference for future research.

$>$ Future research is expected to examine herding behavior in several market conditions in a wider scope, not only limited to the capital market in Indonesia. Research can be carried out in developing capital markets as well as in developed capital markets. Also, research can compare the results between developing and developed capital markets.

$>$ Future research is expected to use different market conditions or add different market conditions so that more varied research results can be obtained and can contribute to the development of knowledge about the capital market, especially the topic of herding behavior.

$>$ Future research is expected to use other methods that can detect herding behavior in various market conditions by distinguishing the behavior of foreign and domestic investors.

\section{REFERENCES}

[1]. Bikhchandani, S., \& Sharma, S. (2000). Herd behaviour in financial markets. IMF Staff Papers, 47(3), 279-310.

[2]. Chang, E. C., Cheng, J. W., \& Khorana, A. (2000). An examination of herd behavior in equity markets: An international perspective. Journal of Banking \& Finance, 24(10), 1651-1679.

[3]. Chiang, T. C., Li, J., \& Tan, L. (2010). Empirical investigation of herding behavior in Chinese stock markets: Evidence from quantile regression analysis. Global Finance Journal, 21(1), 111-124. doi:10.1016/j.gfj.2010.03.005

[4]. Chiang, T. C., \& Zheng, D. (2010). An empirical analysis of herd behavior in global stock markets. Journal of Banking \& Finance, 34(8), 1911-1921. doi:10.1016/j.jbankfin.2009.12.014

[5]. Christie, W. G. and Huang, R. D. (1995) Following the pied piper: do individual returns herd around the market?. Financial Analysts Journal, 51, 31-7. doi:10.2469/faj.v51.n4.1918

[6]. Devenow, A., \& Welch, I. (1996). Rational herding in financial economics. European Economic Review, 40(3-5), 603-615.

[7]. Fama, Eugene (1970). "Efficient Capital Markets: A Review of Theory and Empirical Work". Journal of Finance. 
[8]. Froot, K. A., Scharfstein, D. S., \& Stein, J. C. (1992). Herd on the street: Informational inefficiencies in a market with short-term speculation. The Journal of Finance, 47(4), 1461-1484.

[9]. Gumanti, T. A., \& Utami, E. S. (2002). Bentuk Pasar Efisiensi dan Pengujiannya. Jurnal akuntansi dan Keuangan, 4(1), 54-68.

[10]. Gunawan, H. W., Achsani, N. A., \& Rahman, L. O. A. (2011). Pendeteksian Perilaku Herding pada Pasar Saham Indonesia dan Asia Pasifik. Forum Statistika dan Komputasi, 16, 16-23.

[11]. Hwang, S., \& Salmon, M. (2004). Market stress and herding. Journal of Empirical Finance, 11(4), 585616. doi:10.1016/j.jempfin.2004.04.003

[12]. Indonesia, Bank. (2009). Response Kebijakan Moneter di Tengah Krisis Global. Laporan Perekonomian Indonesia Tahun.

[13]. Lao, P., \& Singh, H. (2011). Herding behaviour in the Chinese and Indian stock markets. Journal of Asian Economics, 22(6), 495-506. doi:10.1016/j.asieco.2011.08.001

[14]. Lintner, A. (1998). Behavioral finance: Why investors make bad decisions. The Planner, 13(1),7-9

[15]. Luo, Z., \& Schinckus, C. (2014). Herding behaviour in asymmetric and extreme situations: the case of China. Applied Economics Letters, 22(11), 869-873. doi:10.1080/13504851.2014.985363

[16]. Phuoc Luong, L., \& Thi Thu Ha, D. (2011). Behavioral factors influencing individual investors' decision-making and performance. : A survey at the Ho Chi Minh Stock Exchange (Dissertation). Retrieved from http://urn.kb.se/resolve?urn=urn:nbn:se:umu:diva44944

[17]. Shiller, R. J. (2003). From efficient markets theory to behavioral finance. Journal of economic perspectives, 17(1), 83-104.

[18]. Tan, L., Chiang, T. C., Mason, J. R., \& Nelling, E. (2008). Herding behavior in Chinese stock markets: An examination of $\mathrm{A}$ and $\mathrm{B}$ shares. Pacific-Basin Finance Journal, 16(1-2), 61-77. 